\title{
INFLUÊNCIA DE PLANTAS DE COBERTURA DE INVERNO NA ESTRUTURA DA COMUNIDADE DA FAUNA EDÁFICA
}

\author{
Winter cover crops influence in edaphic \\ fauna community structure
}

Rodrigo Ferreira Da Silva, Antonio Luis Santi, Claudir José Basso, Gilvan Moises Bertollo e Geomar Mateus Corassa rofesil@bol.com.br

Centro de Educação Superior Norte do Rio Grande do Sul CESNORS - FW

Resumo

A utilização de plantas de cobertura contribui para o manejo do solo, promovendo melhorias em suas características biológicas. O trabalho objetivou determinar a contribuição de plantas de cobertura de inverno na comunidade da mesofauna e da macrofauna edáfica. $\mathrm{O}$ trabalho foi desenvolvido em área experimental da Universidade Federal de Santa Maria, campus Frederico Westphalen, em delineamento blocos casualizados, num fatorial $6 \mathrm{X}_{4}$, sendo seis culturas de cobertura de inverno (aveia branca - Avena sativa L.; azevém - Lolium multiflorum L.; canola - Brassica napus L.; linhaça - Linum usitatissimum L.; triticale - Tritico secale Witt. e área em pousio vegetado) e quatro épocas de coleta (0, 50, 100 e 150 dias após a semeadura), com quatro repetições. As coletas foram realizadas com armadilhas PROVID, permanecendo no campo por 
sete dias. Os indivíduos capturados nas armadilhas foram identificados quanto à classe ou ordem. Foram avaliados a quantidade de indivíduos e os índices de riqueza de Margalef, dominância de Simpson, diversidade de Shannon e equabilidade de Pielou. Com base na quantidade de indivíduos, realizou-se a análise multivariada de agrupamento nas diferentes épocas de coleta. Os resultados revelaram que as plantas de coberturas de inverno contribuem para o aumento da quantidade de indivíduos da fauna do solo. A cultura de cobertura utilizada e seu estádio de desenvolvimento influenciam nos índices de diversidade de Shannon e dominância de Simpson.

Palavras-chave: plantas de cobertura, macrofauna, diversidade, riqueza.

\section{Abstract}

The use of cover crops contributes to soil management by improving their biological characteristics. The aim of this study was to determine the contribution of winter cover crops in mesofauna and macrofauna community. The work was developed at the experimental area of the Federal University of Santa Maria, on Frederico Wesphalen campus, in randomized block design, in a factorial $6 \times 4$, being six winter cover crops (oats - Avena sativa L.; ryegrass - Lolium multiflorum L.; canola - Brassica napus L.; linseed - Linum usitatissimum L.; triticale - Tritico secale Witt. and fallow vegetated area) and four sampling times (O, 50, 100 and 150 days after sowing), with four repetitions. Samples were collected with PROVID traps, staying in the field for seven days. The captured individuals from the traps were identified by class or order. It was evaluated the quantity of individuals and the Margalef richness index, Simpson dominance, Shannon diversity and Pielou evenness. The multivariable analysis of different sampling times was realized based on the number of individuals. The results showed that winter cover crops contribute to increasing amount of individuals of soil fauna. The used cover crop used and its development stage induce the Shannon diversity index and the Simpson dominance.

Keywords: cover crops, macrofauna, diversity, riches 


\section{Introdução}

O impacto provocado pelas práticas agrícolas resulta em redução na densidade dos organismos da macrofauna do solo e, independentemente do manejo, podem ocorrer reduções na diversidade nos sistemas cultivados, quando comparados aos sistemas naturais (SILVA et al., 2006). Segundo Primavesi (2002), a quantidade de seres vivos que pode existir num solo é determinada pela quantidade e qualidade de alimento existente no local (PRIMAVESI, 2002). Desse modo, sistemas monoculturais, ao fornecerem um único substrato alimentar, podem provocar um empobrecimento da diversidade biológica do solo (BARRETA et al., 2003). Como a principal função da biota do solo é a participação nos processos de transformação e fluxo de nutrientes, sua redução acarretará em prejuízos para a qualidade do solo.

As pesquisas no Brasil com variações na fauna edáfica, em resposta a sistemas de cultivo do solo, são ainda incipientes (BARRETA, 2006). Apenas alguns estudos relatam a influência da cobertura vegetal sob a fauna do solo (MOÇO et al., 2005). Steffen et al. (2007) concluíram que a adição de palha moída de nabo ao solo, coletado em área de citros, mostrou-se favorável para a multiplicação de colêmbolos em condição de laboratório. Rovedder et al. (2009) observaram redução da fauna edáfica em solos em processo de arenização na ausência de cobertura vegetal com Lupinus albescens. Loranger et al. (1999) também encontraram redução da população e na riqueza de espécies da ordem Collembola em sítios que perderam a cobertura vegetal. Fiorin (2007) afirma que a utilização de espécies de cobertura do solo possibilita, a curto e médio prazo, restaurar as características biológicas do solo, contribuindo assim para o seu manejo sustentável (ALVARENGA et al., 1995). Segundo Alcântara et al. (2000), as plantas de cobertura ao solo atuam de modo benéfico sobre a reciclagem de nutrientes, agregação do solo, armazenamento da água e a manutenção da matéria orgânica do solo, quando comparadas a monocultivos anuais. Marchão (2007), em estudos conduzidos em um Latossolo no cerrado, afirma que a palhada acumulada pelo uso de plantas de cobertura tende a promover resultados benéficos às comunidades da macrofauna edáfica.

As atividades e a diversidade dos organismos da fauna edáfica refletem as características do manejo do solo. Segundo Silva et al. (2006), a comunidade da macrofauna edáfica é um parâmetro sensível ao im- 
pacto de diferentes tipos de sistemas de produção, o que possibilita seu uso como instrumento na determinação de opções de manejo dos sistemas agropecuários. Devido à rápida resposta que apresentam, esses indivíduos têm sido utilizados como parâmetro biológico na avaliação do grau de modificação a que uma área está sendo submetida (COSTA, 2002). A sensibilidade dos invertebrados do solo aos diferentes manejos reflete o quanto, determinada prática de manejo pode ser considerada ou não conservativa em relação à estrutura e à fertilidade do solo (CORREIA, 2002).

Por possuírem a habilidade de integrar propriedades físicas, químicas e biológicas do ecossistema, esses organismos têm sido considerados bioindicadores de qualidade do solo (DORAN \& ZEISS, 2000). Entretanto, são escassos os estudos a respeito do comportamento das diferentes comunidades edáficas, submetidas a diferentes cultivos de inverno, utilizados como cobertura de solo. O trabalho teve o objetivo de determinar a contribuição dos cultivos invernais de aveia branca, azevém, canola, linhaça e triticale sobre os indivíduos da mesofauna e da macrofauna do solo.

\section{Material e Métodos}

O trabalho foi desenvolvido na área experimental da Universidade Federal de Santa Maria, campus Frederico Westphalen - RS, localizado a uma latitude $27^{\circ} 23^{\prime} 45,75^{\prime \prime}$ S e longitude $53^{\circ} 25^{\prime} 45,92^{\prime \prime} \mathrm{O}$, com uma altitude aproximada de 560 metros. O solo do local é classificado como um Latossolo Vermelho distrófico típico (EMBRAPA, 1999), inicialmente, coberto com gramíneas nativas e, posteriormente, preparado para implantação das culturas de cobertura.

A análise do solo, seguindo metodologia da Embrapa (1997), apresentou as seguintes características físico-químicas: $39 \%$ de argila; $\mathrm{pH}$ $\mathrm{H}_{2} \mathrm{O}$ 6,1; 4,3 mg dm³ de P (Mehlich-1); $114 \mathrm{mg} \mathrm{dm}^{-3}$ de K; 11,6 $\mathrm{cmol}_{\mathrm{c}}$ $\mathrm{dm}^{-3} \mathrm{de} \mathrm{Ca}^{2+} ; 5, \mathrm{O} \mathrm{cmol}_{\mathrm{c}} \mathrm{dm}^{-3} \mathrm{de} \mathrm{Mg}^{2+}$ e 3,4\% de matéria orgânica. A área apresenta relevo suavemente ondulado e o clima da região, segundo Köppen, é do tipo Cfa. A temperatura média anual está em torno $18 \mathrm{fflC}$ e a precipitação média anual entre 1.800 e $2.100 \mathrm{~mm}$ bem distribuídos ao longo do ano (BERNARDI et al. 2007).

O trabalho constou de um levantamento da mesofauna e da macrofauna edáfica em glebas de $100 \mathrm{~m}$. O delineamento utilizado foi em 
blocos casualizados em esquema fatorial $6 \mathrm{X}_{4}$, com seis culturas de cobertura de inverno (aveia branca, azevém, canola, linhaça e triticale e área em pousio com vegetação natural) e quatro épocas de coleta $(0,50$, 100 e 150 dias após a semeadura), com quatro repetições. A primeira coleta foi realizada antes da implantação das culturas, com o solo totalmente revolvido, manejado sob sistema convencional, e foi utilizada como parâmetro inicial para todos os cultivos estudados. Nessa coleta, foi capturada a quantidade de 240 indivíduos, distribuídos em seis diferentes ordens, sendo: Acarina, Araneae, Coleoptera, Collembola, Díptera e Hymenoptera.

A segunda coleta (50 dias) foi realizada ao pleno desenvolvimento das culturas, a terceira coleta (100 dias), durante a fase reprodutiva das culturas e a quarta coleta (150 dias) ao final do ciclo das culturas, quando estas se apresentavam na forma de cobertura de solo.

As coletas foram realizadas com o auxílio das armadilhas tipo PROVID, propostas por Antoniolli et al. (2006). As armadilhas permaneceram no campo por um período de sete dias, contendo em seu interior $200 \mathrm{~mL}$ de álcool 70\% para conservação dos insetos capturados. Os indivíduos retirados das armadilhas foram identificados quanto à classe ou ordem, com auxílio de lupas binoculares com aumento de 40 vezes.

A partir da contagem e identificação em nível de ordem ou classe dos organismos edáficos, utilizando-se chaves ilustradas de identificação (BUZZI, 2008), foram calculados: a quantidade total de indivíduos e os índices de riqueza de Margalef e dominância de Simpson, conforme descritos por Odum (1986), e o índice de diversidade de Shannon (SHANNON E WEAVER, 1949). Para a análise da uniformidade da comunidade, foi utilizado o índice de equabilidade de Pielou (PIELOU, 1977).

Os índices de riqueza de Margalef, dominância de Simpson, diversidade de Shannon e equabilidade de Pielou foram submetidos à transformação $(\mathrm{X}+0,5)^{0,5} \mathrm{e}$, posteriormente, juntamente com os demais parâmetros avaliados, ao teste F. Após, para os efeitos significativos, as médias foram comparadas pelo teste de Tukey ao nível de $5 \%$ de significância, utilizando-se o programa estatístico SISVAR (FERREIRA, 2008). Para a análise multivariada de agrupamento (Cluster), utilizou-se a "distância euclidiana" para a quantidade de indivíduos, obtida nas diferentes culturas de cobertura para as diferentes épocas de coleta, por meio do programa STATISTICA 7.0 (STATSOFT, 2004). 


\section{Resultado e Discusão}

Os resultados das coletas das armadilhas instaladas nas seis áreas avaliadas revelaram a presença de indivíduos da fauna do solo distribuídos nos grupos: Acarina, Aranae, Anura, Collembola, Coleóptera, Díptera, Hemiptera, Hymenoptera, Lepdóptera, Orthoptera e Pulmonata (Tabela 1). Verifica-se que, aos 50 dias, foi identificada uma quantidade total de 1262 indivíduos. Aos 100 dias, os indivíduos representaram um total de 1157 e, aos 150 dias, um total de 994 indivíduos (Tabela 1).

Considerando a presença de apenas 240 indivíduos na primeira coleta (tempo zero), tem-se uma amplitude de 1022 indivíduos. Esse aumento, segundo Brown et al. (2003), deve-se ao efeito direto do preparo inicial do solo sobre as populações menos adaptadas ao impactos mecânicos provocados. O decréscimo na quantidade total de indivíduos advindo dos 50 para os 150 dias se deve à redução nas populações das ordens Collembola e Acarina, as quais reduziram, respectivamente, 19 e $64 \%$. A ordem collembola representou 64,57 e $65 \%$ da quantidade total de indivíduos nas coletas dos 50, 100 e 150 dias, respectivamente, enquanto que a população da ordem Acarina representou 16, 4 e 7\%, respectivamente.

Tabela 1: Número, total e quantidade de indivíduos coletados para cada classe/ordem nos cultivos de triticale, aveia branca, azevém, linhaça, canola e pousio aos 50, 100 e 150 dias após semeadura das culturas. Frederico Westphalen, RS, 2010.

\begin{tabular}{cccccccc}
\hline & \multicolumn{7}{c}{ CULTIVOS } \\
\cline { 2 - 8 } Ordem/Classe & Tricale $\begin{array}{c}\text { Aveia } \\
\text { branca }\end{array}$ & Azevém & Linhaça & Canola & Pousio & TOTAL \\
\cline { 2 - 8 } Acarina & 46 & 14 & 52 & 28 & 48 & 11 & 199 \\
Araneae & 1 & 0 & 1 & 1 & 1 & 1 & 5 \\
Collembola & 59 & 28 & 320 & 145 & 182 & 75 & 809 \\
Coleoptera & 7 & 0 & 1 & 2 & 3 & 3 & 16 \\
Díptera & 8 & 6 & 4 & 1 & 2 & 11 & 32 \\
Hemiptera & 9 & 8 & 3 & 5 & 8 & 3 & 36 \\
Hymenoptera & 45 & 11 & 25 & 29 & 15 & 36 & 161 \\
Larvas & 0 & 1 & 0 & 0 & 0 & 0 & 1 \\
Orthoptera & 0 & 0 & 1 & 1 & 1 & 0 & 3 \\
Quantidade & 175 & 68 & 407 & 212 & 260 & 140 & 1262 \\
\hline
\end{tabular}




\begin{tabular}{|c|c|c|c|c|c|c|c|}
\hline \multirow[b]{2}{*}{ Acarina } & \multicolumn{7}{|c|}{100 DIAS } \\
\hline & 17 & 12 & 4 & 8 & 6 & 2 & 49 \\
\hline Anura & o & ○ & 1 & ० & 1 & 1 & 3 \\
\hline Araneae & 8 & 10 & 4 & 4 & 2 & 2 & 30 \\
\hline Collembola & 50 & 36 & 102 & 76 & 261 & 131 & 656 \\
\hline Coleoptera & 15 & 21 & 29 & 11 & 4 & 10 & 90 \\
\hline Díptera & 39 & 37 & 15 & 6 & 6 & 14 & 117 \\
\hline Hymenoptera & 42 & 36 & 30 & 21 & 35 & 30 & 194 \\
\hline Larvas & 1 & 1 & 3 & 1 & $\circ$ & 1 & 7 \\
\hline Lepdóptera & o & o & ० & ० & 1 & o & 1 \\
\hline Orthoptera & o & 0 & 2 & 3 & 4 & 1 & 10 \\
\hline \multirow[t]{2}{*}{ Quantidade } & 172 & 153 & 190 & 130 & 320 & 192 & 1157 \\
\hline & \multicolumn{7}{|c|}{150 DIAS } \\
\hline Acarina & 10 & 8 & 13 & 13 & 10 & 17 & 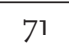 \\
\hline Araneae & 3 & 2 & 7 & 5 & 3 & 8 & 28 \\
\hline Collembola & 88 & 56 & 197 & 197 & 49 & 68 & 655 \\
\hline Coleoptera & 10 & 3 & 3 & 9 & 4 & 18 & 47 \\
\hline Díptera & 5 & 3 & 8 & 1 & o & $\circ$ & 17 \\
\hline Hemíptera & 2 & 0 & 4 & ० & $\circ$ & 2 & 8 \\
\hline Hymenoptera & 39 & 10 & 18 & 17 & 35 & 32 & 151 \\
\hline Larvas & $\circ$ & $\circ$ & 1 & 1 & 1 & $\circ$ & 3 \\
\hline Lepdóptera & 1 & o & ० & ० & ० & 1 & 2 \\
\hline Orthoptera & 2 & 1 & 2 & 1 & 3 & 2 & 11 \\
\hline Pulmonata & 1 & 0 & 0 & o & 0 & 0 & 1 \\
\hline Quantidade & 161 & 83 & 253 & 244 & 105 & 148 & 994 \\
\hline Acumulado & 508 & 304 & 850 & 586 & 685 & 480 & 3413 \\
\hline
\end{tabular}

As ordens Collembola e Acarina são consideradas as mais abundantes da mesofauna e servem como indicadores das condições biológicas do solo, devido a sua sensibilidade às condições ambientais (DAMÉ et al., 1996). A presença dessas populações é importante na mistura do solo e na decomposição de resíduos orgânicos (FISHER \& BINKLEY, 2000).

A ordem Hymenoptera, representada basicamente por formigas, também apresentou indivíduos em todas as épocas de coleta. Essa ordem representou 15\% do total de indivíduos coletados (Tabela 1). Resultados superiores foram encontrados por Silva et al. (2006) em trabalhos conduzidos sob sistema de plantio direto, em que a ordem Hymenoptera representou $38 \%$ do total. Esses organismos são importantes para os processos de decomposição, além de serem descritos como engenhei- 
ros ecológicos do solo, pois contribuem para processos fundamentais, como a estimulação da atividade microbiana, formação da estrutura do solo e dinâmica da matéria orgânica (LAVELLE \& SPAIN, 2001).

O número de indivíduos da ordem Collembola encontrado aos 50 dias foi maior para o cultivo do azevém, apesar de não diferir dos cultivos de canola e linhaça (Tabela 2). Aos 100 dias, a cultura de canola foi a que apresentou o maior número de indivíduos da ordem Collembola, enquanto que, triticale e aveia branca apresentaram os menores valores (Tabela 2). Chauvat et al. (2003) relataram que a diversidade da estrutura da cobertura vegetal pode influenciar na distribuição das comunidades da ordem Collembola. Entretanto, aos 150 dias, sua população não apresentou diferença significativa entre os cultivos (Tabela 2).

Segundo Coleman \& Grossley (1995), os Collembola são considerados oportunistas por se desenvolverem mais em condições adequadas, como na presença de material orgânico. Isso indica que, ao final do ciclo das culturas de cobertura, bem como, na área de pousio, as condições ambientais proporcionadas foram semelhantes e não influenciaram decisivamente na população desses indivíduos.

Tabela 2: Número de indivíduos da ordem Collembola, quantidade de indivíduos e índice de riqueza de Margalef nos cultivos de aveia branca, azevém, canola, linhaça, pousio e triticale, nas coletas de 50, 100 e 150 dias. Frederico Westphalen, RS, 2010.

\begin{tabular}{|c|c|c|c|}
\hline \multirow{2}{*}{ Cultivos } & \multicolumn{3}{|c|}{ Período (dias) } \\
\hline & 50 & 100 & 150 \\
\hline & \multicolumn{3}{|c|}{ Collembola } \\
\hline Aveia branca & $28 * \mathrm{Ab}$ & $36 \mathrm{Ab}$ & $56 \mathrm{Aa}$ \\
\hline Azevém & $320 \mathrm{Aa}$ & $102 \mathrm{Bab}$ & $197 \mathrm{ABa}$ \\
\hline Canola & $182 \mathrm{ABab}$ & $261 \mathrm{Aa}$ & $49 \mathrm{Ba}$ \\
\hline Linhaça & 145 Aab & $76 \mathrm{Aab}$ & $197 \mathrm{Aa}$ \\
\hline Pousio & $75 \mathrm{Ab}$ & $131 \mathrm{Aab}$ & $68 \mathrm{Aa}$ \\
\hline Triticale & $59 \mathrm{Ab}$ & $50 \mathrm{Ab}$ & $88 \mathrm{Aa}$ \\
\hline \multirow[t]{2}{*}{$\mathrm{CV}(\%)$} & & 51 & \\
\hline & \multicolumn{3}{|c|}{ Quantidade de indivíduos } \\
\hline Aveia branca & $68 \mathrm{Ac}$ & $153 \mathrm{Aa}$ & $83 \mathrm{Ab}$ \\
\hline Azevém & $407 \mathrm{Aa}$ & $190 \mathrm{Aa}$ & $253 \mathrm{Aab}$ \\
\hline Canola & $260 \mathrm{ABab}$ & $320 \mathrm{Aa}$ & $105 \mathrm{Bab}$ \\
\hline
\end{tabular}




\begin{tabular}{cccc} 
Linhaça & $212 \mathrm{Aabc}$ & $130 \mathrm{Aa}$ & $244 \mathrm{Aa}$ \\
Pousio & $140 \mathrm{Abc}$ & $192 \mathrm{Aa}$ & $148 \mathrm{Aab}$ \\
Triticale & $175 \mathrm{Aabc}$ & $172 \mathrm{Aa}$ & $161 \mathrm{Aab}$ \\
\hline CV $(\%)$ & 25.21 & \\
& & Riqueza de Margalef \\
Aveia branca & $2,62 \mathrm{Aa}$ & $2,53 \mathrm{Aa}$ & $2,59 \mathrm{Aab}$ \\
Azevém & $1,92 \mathrm{Aa}$ & $2,64 \mathrm{Aa}$ & $2,53 \mathrm{Aab}$ \\
Canola & $2,34 \mathrm{Aa}$ & $2,80 \mathrm{Aa}$ & $2,72 \mathrm{Aab}$ \\
Linhaça & $2,19 \mathrm{Aa}$ & $2,83 \mathrm{Aa}$ & $2,26 \mathrm{Aab}$ \\
Pousio & $2,49 \mathrm{Aa}$ & $2,56 \mathrm{Aa}$ & $1,97 \mathrm{Ab}$ \\
Triticale & $2,46 \mathrm{Ba}$ & $2,69 \mathrm{Ba}$ & $3,5 \mathrm{Aa}$ \\
\hline CV $(\%)$ & & 13.99 & \\
\hline
\end{tabular}

* Médias seguidas de mesma letra minúscula na coluna e maiúscula na linha não diferem entre si pelo teste de Tukey a $5 \%$ de probabilidade de erro.

A maior quantidade de indivíduos, coletados aos 50 dias, foi observada no cultivo com azevém, seguido do cultivo de canola, linhaça e triticale, enquanto que as menores quantidades foram obtidas no cultivo de aveia branca (Tabela 2). Aos 150 dias, a linhaça apresentou a maior quantidade de indivíduos, sendo as menores quantidades obtidas no cultivo de aveia branca (Tabela 2). Entretanto, aos 100 dias, não houve diferença significativa para a quantidade de indivíduos entre os cultivos.

Conforme Lavelle et al. (1992), a quantidade de alimento pode influenciar na quantidade de indivíduos, pois a menor produção de matéria seca pode inferir na disponibilidade de substrato para a macrofauna, favorecendo a população mais numerosa ou melhor adaptada a esse ambiente. Além disso, os resíduos vegetais, mantidos na superfície do solo podem proporcionar ambiente favorável para a sobrevivência de determinados grupos da fauna edáfica (MOÇO et al., 2005). Conforme Chauvat et al. (2003), a maior quantidade pode ser influenciada também pela qualidade do material vegetal. Desse modo, nas fases iniciais, as áreas cultivadas com azevém podem contribuir para o aumento da quantidade de indivíduos, quando comparada aos demais cultivos.

Para o índice de riqueza de Margalef, os cultivos não apresentaram diferença significativa aos 50 e 100 dias, porém, aos 150 dias, a cultura do triticale mostrou-se superior aos demais, enquanto que os resultados mais inferiores foram observados no tratamento pousio (Tabela 2). Os resultados desse trabalho demonstram que, aos 150 dias, as plantas de 
cobertura utilizadas favoreceram, de modo geral, a riqueza de indivíduos, quando comparados à área de pousio, e que a utilização de triticale como planta de cobertura proporcionou um aumento gradativo na riqueza de Margalef durante o período avaliado (Tabela 2).

O índice de equabilidade de Pielou, obtido na coleta aos 50 dias, foi superior na cultura da aveia branca, seguida de triticale e pousio, enquanto que, aos 100 dias, aveia branca e linhaça, seguidos por triticale, azevém e pousio, obtiveram os maiores índices (Tabela 3). Os resultados semelhantes obtidos entre os cultivos e o tratamento pousio, devem-se possivelmente à presença de uma maior diversidade de espécies de plantas no tratamento pousio, o que proporciona um ambiente favorável à sobrevivência de grupos da fauna. Segundo Agostinetto (2000), a cobertura da superfície do solo contribui para a manutenção das taxas de infiltração de água, acúmulo de matéria orgânica no solo e para a presença de indivíduos edáficos.

Tabela 3: Índice de equabilidade de Pielou, dominância de Simpson e diversidade de Shannon nos cultivos de aveia branca, azevém, canola, linhaça, triticale e pousio, obtidos nas coletas ao o, 50, 100 e 150 dias após semeadura das culturas. Frederico Westphalen, RS, 2010.

\begin{tabular}{|c|c|c|c|c|}
\hline \multirow[b]{2}{*}{ Cultivos } & \multicolumn{4}{|c|}{ Período (dias) } \\
\hline & $0 * *$ & 50 & 100 & 150 \\
\hline & \multicolumn{4}{|c|}{ Equabilidade de Pielou } \\
\hline Aveia Branca & $0.54 \mathrm{Ca}^{*}$ & $0.85 \mathrm{Aba}$ & $0.88 \mathrm{Aa}$ & $0.58 \mathrm{BCab}$ \\
\hline Azevém & $0.54 \mathrm{Aa}$ & $0.40 \mathrm{Ac}$ & $0.63 \mathrm{Aab}$ & $0.49 \mathrm{Aab}$ \\
\hline Canola & $0.54 \mathrm{ABa}$ & $0.54 \mathrm{ABbc}$ & $0.34 \mathrm{Bb}$ & $0.68 \mathrm{Aab}$ \\
\hline Linhaça & $0.54 \mathrm{Aa}$ & $0.53 \mathrm{Abc}$ & $0.68 \mathrm{Aa}$ & $0.43 \mathrm{Ab}$ \\
\hline Pousio & $0.54 \mathrm{Aa}$ & $0.64 \mathrm{Aab}$ & $0.56 \mathrm{Aab}$ & $0.76 \mathrm{Aa}$ \\
\hline Triticale & $0.54 \mathrm{Ba}$ & $0.77 \mathrm{ABab}$ & $0.85 \mathrm{Aa}$ & $0.64 \mathrm{ABab}$ \\
\hline \multirow[t]{2}{*}{ CV (\%) } & \multicolumn{4}{|c|}{7.2} \\
\hline & \multicolumn{4}{|c|}{ Dominância de Simpson } \\
\hline Aveia Branca & $0.55 \mathrm{Aa}$ & $0.27 \mathrm{BCb}$ & $0.22 \mathrm{Cb}$ & $0.51 \mathrm{ABa}$ \\
\hline Azevém & $0.55 \mathrm{Aa}$ & $0.64 \mathrm{Aa}$ & $0.43 \mathrm{Aab}$ & $0.38 \mathrm{Ba}$ \\
\hline Canola & $0.55 \mathrm{Aa}$ & $0.50 \mathrm{ABab}$ & $0.68 \mathrm{Aa}$ & $0.64 \mathrm{Aa}$ \\
\hline Linhaça & $0.55 \mathrm{Aa}$ & $0.52 \mathrm{Aab}$ & $0.39 \mathrm{Aab}$ & $0.38 \mathrm{Aa}$ \\
\hline Pousio & $0.55 \mathrm{Aa}$ & $0.37 \mathrm{Aab}$ & $0.49 \mathrm{Aab}$ & $0.37 \mathrm{Aa}$ \\
\hline Triticale & $0.55 \mathrm{Aa}$ & $0.29 \mathrm{ABb}$ & $0,22 \mathrm{Bb}$ & $0.37 \mathrm{ABa}$ \\
\hline CV $(\%)$ & \multicolumn{4}{|c|}{7.61} \\
\hline
\end{tabular}




\begin{tabular}{ccccc} 
& \multicolumn{4}{c}{ Diversidade de Shannon } \\
Aveia Branca & $0.33 \mathrm{Ba}$ & $0.54 \mathrm{Aab}$ & $0.71 \mathrm{Aa}$ & $0.43 \mathrm{ABa}$ \\
Azevém & $0.33 \mathrm{Aa}$ & $0.31 \mathrm{Ab}$ & $0.53 \mathrm{Aab}$ & $0.41 \mathrm{Aa}$ \\
Canola & $0.33 \mathrm{Aa}$ & $0.43 \mathrm{Aab}$ & $0.30 \mathrm{Ab}$ & $0.54 \mathrm{Aa}$ \\
Linhaça & $0.33 \mathrm{Aa}$ & $0.41 \mathrm{Aab}$ & $0.56 \mathrm{Aab}$ & $0.34 \mathrm{Aa}$ \\
Pousio & $0.33 \mathrm{Aa}$ & $0.54 \mathrm{Aab}$ & $0.46 \mathrm{Aab}$ & $0.52 \mathrm{Aa}$ \\
Triticale & $0.33 \mathrm{Ba}$ & $0.62 \mathrm{Aa}$ & $0.71 \mathrm{Aa}$ & $0.59 \mathrm{ABa}$ \\
CV $(\%)$ & & \multicolumn{3}{c}{7.93} \\
\hline
\end{tabular}

* Médias seguidas de mesma letra minúscula na coluna e maiúscula na linha não diferem entre si pelo teste de Tukey a $5 \%$ de probabilidade de erro. ** Valores do tempo zero (o) referente à avaliação da fauna edáfica em toda área do experimento, antes da instalação dos cultivos.

Aos 150 dias, o cultivo de linhaça apresentou os menores resultados para a equabilidade de Pielou, enquanto que pousio apresentou os melhores resultados (Tabela 3). Nesse período, o tratamento pousio apresentou a maior porcentagem relativa de biomassa seca acima do solo em relação às demais culturas de cobertura de inverno (Figura 1) e isso pode ter favorecido a melhor uniformidade de grupos edáficos. Os cultivos de canola, aveia branca, azévem, triticale também apresentaram resultados semelhantes, contudo, não diferiram entre si (Tabela 3). Fiorin (2007) salienta que a cultura da canola apresenta baixa relação C/N, o que favorece a rápida decomposição, e pode contribuir para a presença da fauna do solo. As gramíneas por sua vez possuem alta relação $\mathrm{C} / \mathrm{N}$, o que reduz a taxa de decomposição de resíduos orgânicos (AITA et al., 2004), possibilitando a formação e a manutenção de uma cobertura mais estável para as comunidades da fauna do solo.

Os maiores valores de dominância de Simpson, aos 50 e 100 dias, ocorreram, respectivamente, na cultura do azevém e na cultura da canola (Tabela 3). Os resultados desse trabalho estão de acordo com os encontrados por Alves et al. (2008), que verificaram que os resultados de dominância se devem possivelmente ao efeito do tipo de cobertura do solo. Segundo Pinheiro (2004), cada comunidade de um ecossistema responderá diferentemente a impactos sofridos, diferindo no grau de sensibilidade e de recuperação. A dominância nas áreas avaliadas se deve possivelmente à presença da ordem Collembola, que, nos cultivos de canola e azevém, representaram, respectivamente, $78 \%$ e $82 \%$ do total de indivíduos (Tabela 2). Nesse caso, a dominância não pode ser con- 
siderada um fator negativo, afinal, a ordem Collembola desempenha importante papel para a manutenção da qualidade dos solos (FISHER \& BINKLEY, 2000). Aos 150 dias, não houve diferença significativa entre os cultivos para o índice de dominância.

O índice de diversidade Shannon, observado aos 50 dias, foi maior na cultura do triticale (Tabela 3). Aos 100 dias, triticale e aveia branca apresentaram os maiores índices de diversidade, enquanto que o menor valor ocorreu nos cultivos com canola. Entretanto, aos 150 dias, os cultivos não apresentaram diferença significativa na diversidade de espécies (Tabela 3). Segundo Baretta et al. (2003), a perda de diversidade ocorre devido à presença de espécies dominantes, favorecidas pelo ambiente da parcela ou pelo fornecimento de um único substrato alimentar. Por outro lado, a presença de cobertura permanente no solo contribui para o aumento de energia, associada à existência de novos habitats favoráveis à colonização dos organismos invertebrados (SILVA et al., 2007).

Em relação aos períodos avaliados, nota-se que, no período compreendido como a fase reprodutiva das culturas (100 dias), as áreas com aveia branca e triticale apresentaram menor dominância de Simpson (Tabela 3). Dessa forma, para este mesmo período, as áreas cultivadas com triticale e a aveia branca apresentaram maior diversidade de Shannon (Tabela 3). Canto (1996) relata que as culturas de inverno auxiliam com incrementos de matéria seca e protegem o solo das intempéries climáticas, formando uma camada espessa com vários estratos de matéria fresca, capaz de abrigar uma fauna mais diversificada. Desse modo, ao comparar as coletas dos 150 dias em relação ao tempo zero, os cultivos de triticale, canola, pousio, aveia branca e azevém proporcionaram aumento na diversidade de 78\%, 60\%, 57\%, 30\% e 18\%, respectivamente.

Para a porcentagem relativa (\%) de biomassa seca acima do solo (Figura 1), a área em pousio apresentou um aumento gradativo ao longo do período de avaliação, sendo maior aos 150 dias. Isso ocorreu pelo fato de que o tratamento, por não ter sido manejado, apresentou espécies em desenvolvimento vegetativo durante todo o período, diferente dos demais cultivos, em que a culturas, após os estádios reprodutivos, atingiram a maturidade fisiológica e posteriormente a senescência.

Sabe-se que a redução na disponibilidade de palha remanescente sobre o solo provoca a diminuição da diversidade de organismos (GATIBONI et al., 2009), o que ficou evidenciado pelos baixos índices de di- 
versidade, obtidos na primeira coleta. Entretanto, na área com azevém, embora tenha ocorrido redução na biomassa seca dos 50 para os 150 dias (Figura 1), não houve diferença significativa para o índice de diversidade de Shannon (Tabela 3). Isso pode indicar que somente a manutenção de palhada sobre o solo já é um fator mantenedor da diversidade biológica e que não somente a quantidade de biomassa, mas também a sua qualidade pode influenciar na diversidade da fauna do solo.

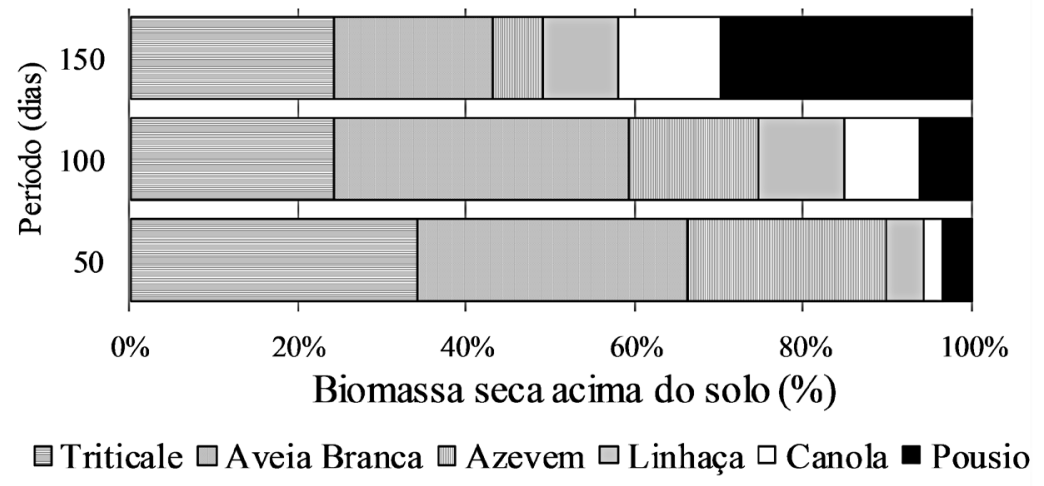

Figura 1. Porcentagem relativa de biomassa seca acima do solo (\%) nas áreas de cultivo de triticale, aveia branca, azevém, linhaça, canola e pousio aos 50 , 100 e 150 dias após plantio. Frederico Westphalen, RS, 2010.

A análise de agrupamento baseada na quantidade de indivíduos evidenciou, aos 50 dias, um grupamento formado pelo tratamento pousio e triticale com 35 indivíduos, seguido por grupos isolados formados pela linhaça com 37 indivíduos, canola com 48 , aveia branca com 72 e azévem com 147 indivíduos (Figura 2). Isso significa que pousio e triticale são áreas com $65 \%$ de similaridade na quantidade de indivíduos.

Aos 100 dias, há a formação de um grupo representado pelo pousio e azévem com 2 indivíduos, seguido pelos cultivos de triticale, aveia branca e linhaça, que juntos apresentam distância euclidiana máxima de 23 indivíduos (Figura 2). Desse modo, pela análise de agrupamentos, pode-se inferir que, no período de florescimento, com exceção da canola, as culturas de cobertura de inverno apresentam menor distância 


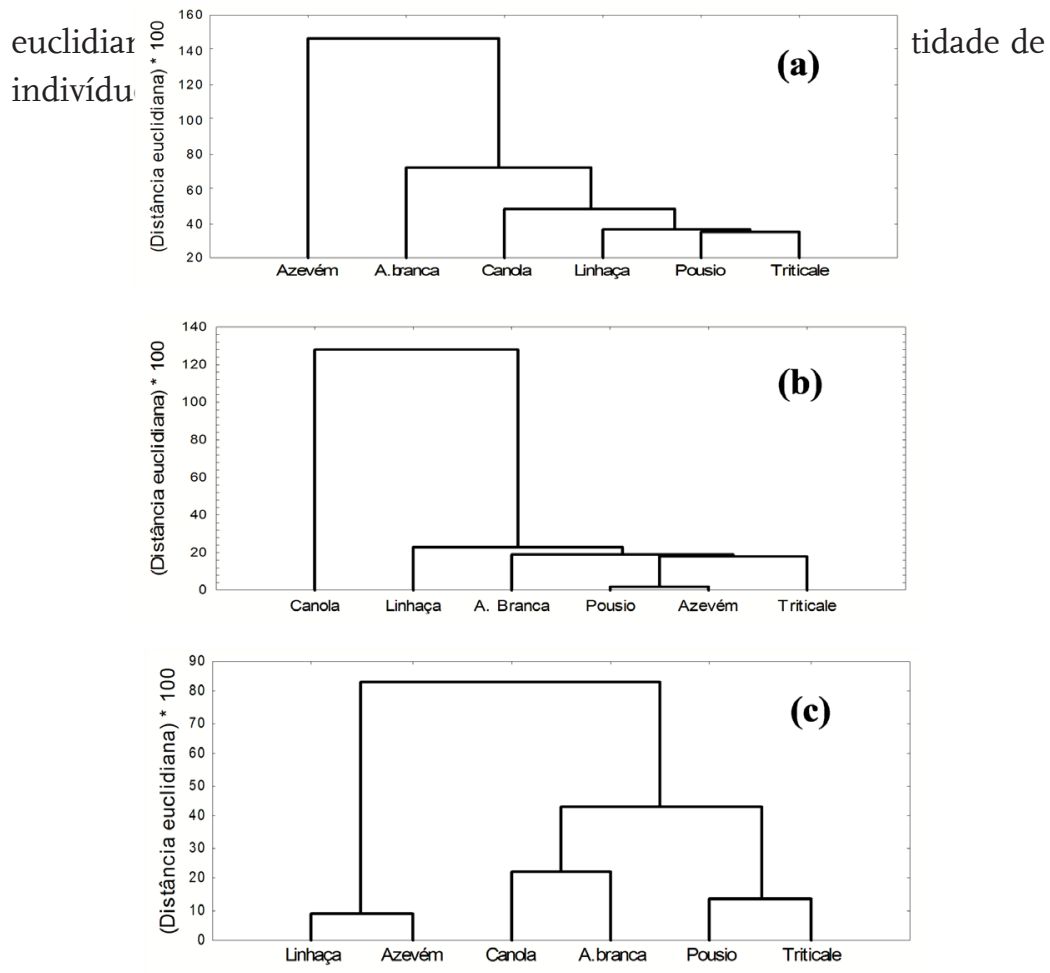

Figura 2. Dendrograma apresentando a distância de ligação referente à quantidade de indivíduos da fauna do solo nos diferentes sistemas de cultivo, aos 50 (a), 100 (b) e 150 dias (c) após a implantação das culturas. Frederico Westphalen, RS, 2010.

Aos 150 dias, ocorreu a formação de três grupos distintos (Figura 2). O primeiro grupo é formado por linhaça e azévem, representando distância euclidiana de 9 indivíduos. O segundo grupo é formado por pousio e triticale, com distância de 13 indivíduos, e o terceiro grupo, pelos cultivos de canola e aveia branca com 22 indivíduos. Isso resultou em uma similaridade de $91 \%$ entre linhaça e azevém, $87 \%$ entre pousio e triticale e $78 \%$ entre canola e aveia branca, evidenciando um efeito semelhante entre tais cultivos, em relação à quantidade de indivíduos. Conforme Baretta et al. (2006b), os resultados de análise de agrupamento reforçam a importância dos estudos que visam a discriminar sis- 
temas de cultivo do solo, e entender melhor a dinâmica dos principais grupos da fauna edáfica.

Os resultados obtidos permitem identificar a existência de comportamentos distintos, com base na quantidade de organismos, entre as diferentes culturas de cobertura de inverno. Isso comprova a existência de uma contribuição característica de cada cultivo ou de grupos de cultivo, para a dinâmica das populações da mesofauna e da macrofauna edáfica.

\section{Conclusão}

A utilização de plantas de cobertura de inverno contribui para o aumento da quantidade de indivíduos da fauna do solo; a cultura utilizada e o estádio de desenvolvimento influenciam nos índices de diversidade de Shannon e dominância de Simpson.

\section{Referências Bibliográficas}

AGOSTINETTO, D.; FERREIRA, F. B.; STOCH, G.; FERNANDES, F. F.; PINTO, J. J. O. Adaptação de espécies utilizadas para cobertura de solo no sul do Rio Grande do Sul. Revista Brasileira de Agrociência, v. 6, n. 1, p. 47-52, 2000.

AITA, C.; GIACOMINI, S. J.; HUBNER, A. P.; CHIAPINOTTO, I. C.; FRIES, M. R. Consorciação de plantas de cobertura no outono/inverno antecedendo o milho em plantio direto: Dinâmica do nitrogênio no solo. Revista Brasileira de Ciência do Solo, n. 28, p. 739-749, 2004.

ALCÂNTARA, F.A.; FURTINI NETO, A.E.; PAULA, M.B.; MESQUITA, H.A.; MUNIZ, J.A. Adubação verde na recuperação da fertilidade de um Latossolo Vermelho-Escuro degradado. Pesquisa Agropecuária Brasileira, v.35, p.277-288, 2000.

ALVARENGA, R.C.; COSTA, L.M.; MOURA FILHO, W.; REGAZZI, A.J. Características de alguns adubos verdes de interesse para a conservação e recuperação de solos. Pesquisa Agropecuária Brasileira, v.30, p.175-185, 1995 .

ALVES, M. V.; SANTOS, J. C. P.; GOIS, D. T. de; ALBERTON, J. V.; BARETTA, D. Macrofauna do solo influenciada pelo uso de fertilizantes químicos e dejetos de suínos no oeste do estado de Santa Catarina. Revista Brasileira de Ciência do Solo. n. 32, p. 589-598, 2008. 
ANTONIOLLI, Z. I.; CONCEIÇÃO, P. C.; BÖCK, V.; PORT, O.; SILVA, D. M. da; SILVA, R. F. da. Método alternativo para estudar a fauna do solo. Ciência Florestal, Santa Maria, v. 16, n. 4, p. 407-417, 2006.

BARETTA, D. MAFRA, Á. L.; SANTOS, J. C. P.; AMARANTE, C. V. T. do; BERTOL, I. Análise multivariada da fauna edáfica em diferentes sistemas de preparo e cultivo do solo. Pesquisa Agropecuária Brasileira, Brasília, v. 41. n. 11. p. 1675-1679, 2006 a.

BARETTA, D.; BROWN, G. G.; JAMES, S. W.; CARDOSO, E. J. B. N. Earthworm opulations sampled using collection methods in Atlantic forests with Araucaria angustifolia. Scientia Agricola, v. 64, p. 384-392, 2007.

BARETTA, D.; SANTOS, J. C. P.; BERTOL, I.; ALVES, M. V.; MANFOI, A. F.; BARETTA, C. R. D. M. Efeito do cultivo do solo sobre a diversidade da fauna edáfica no planalto sul catarinenser. Revista de Ciências Agroveterinárias, Lages, v. 5, n. 2, p. 108-117, 2006b.

BARETTA, D.; SANTOS, J. C. P.; MAFRA, A. L.; WIKDNER, L. P.; MIQUELLUTI, D. J. Fauna edáfica avaliada por armadilhas de catação manual afetada pelo manejo do solo na região oeste catarinense. Revista Ciência Agroveterinárias, v. 2, p. 97-106, 2003.

BERNARDI, I.P., PULCHÉRIO-LEITE, A., IRANDA, J.M.D. \& PASSOS, F.C. Ampliação da distribuição de Molossops neglectus Williams e Genoways (Chiroptera, Molossidae) para o Sul da América do Sul. Revista Brasileira de Zoologia. Curitiba, p. 505-507, 2007.

BUZZI, Z.J. Entomologia Didática. $4^{\circ}$ ed. Curitiba, Editora UFPR. 2008.348p.

CANTO, A. C. Alterações da mesofauna do solo causadas pelo uso de cobertura com plantas leguminosas na Amazônia Central. Revista Ciências Agrárias, v. 4, n. 5, p. 79-94, 1996.

CHAUVAT, M.; ZAITSEV, A. S. \& WOLTERS, V. Successional changes of Collembola and soil microbiota during forest rotation. Oecologia, v. 137, n. 2, p. 269-276, 2003.

COLEMAN, D. C.; GROSSLEY, D. A. Fundamentals of soil ecology. San Diego: Academic Press, 1995. 205p. 
CORREIA, M. E. F. Potencial de utilização dos atributos das comunidades de fauna de solo e de grupos chave de invertebrados como bioindicadores do manejo de ecossistemas. Seropédica: Embrapa Agrobiologia, Documentos, n. 157. 2002. 23p.

COSTA, P. Fauna do solo em plantios experimentais de Eucalyptus grandis Maiden, Pseudosamanea guachapele Dugand e Acacia mangium Wil ld. Instituto de Agronomia - Seropédica, 2002. 93p. Dissertação Mestrado Universidade Federal Rural do Rio de Janeiro.

DAMÉ, P. R. V.; QUADROS, F. L. F.; KERSTING, C. E. B.; TRINDADE, J. P. P.; ANTONIOLLI, Z. I. Efeitos da queimada seguida de pastoreio ou diferimento sobre o resíduo, temperatura do solo e mesofauna de uma pastagem natural. Ciência Rural, Santa Maria, v. 26, p. 391-396, 1996.

DORAN, J. W.; ZEISS, M. R. Soil health and sustainability: managing the biotic vompont of soil quality. Applied Soil Ecology, n. 15, p. 3-11, 2000 .

EMBRAPA - EMPRESA BRASILEIRA DE PESQUISA AGROPECUÁRIA. Manual de métodos de análises de solo, 2.ed. Rio de Janeiro, Ministério da Agricultura e do Abastecimento, 1997. 212p.

EMPRESA BRASILEIRA DE PESQUISA AGROPECUÁRIA. Centro Nacional de Pesquisa de Solos. Sistema Brasileiro de Classificação de Solo. Brasília, Embrapa Produção de Informações, 1999. 412p.

FERREIRA, D. F. SISVAR: um programa para análises e ensino de estatística. Revista Symposium. Lavras, v. 6, p. 36-41, 2008.

FIORIN, J. E. Manejo e fertilidade do solo no sistema plantio direto. Passo Fundo, v. 1, 2007. 184p.

FISHER, R. F.; BINKLEY, D. Ecology and management of forest soils, 3. ed. London: John Wiley, 2000. 489p.

GATIBONI, L. C.; COIMBRA, J. L. M.; WILDNER, L. do P.; DENARDIN, R. B. N. Modificações na fauna edáfica durante a decomposição da palhada de centeio e aveia preta, em sistema plantio direto. Biotemas, v. 22, p. 45-53, 2009 . 
LAVELLE, P.; BLANCHART, E.; MARTIN, A.; SPAIN, A.V.; MARTIN, S. Impact of soil fauna on the properties of soils in the humid tropics. Soil Science Society America Journal: Special Publication, n. 29 p. 157$185,1992$.

LAVELLE, P.; SPAIN, A. V. Soil ecology. Dordrecht: kluwer Academic, 2001. 654p.

LORANGER, G.; PONGE, J. F.; BLANCHART, E.; LAVELLE, P. Influence of agricultural practices on arthropod communities in a vertisol (Martinique). European Journal of Soil Biology, v. 34, n. 3, p. 157-165, 1999.

MARCHÃO, R.L. Integração lavoura-pecuária num Latossolo do Cerrado: impacto na física, matéria orgânica e macrofauna.153p. Tese (Doutorado) - Universidade Federal de Goiás, Goiânia. 2007.

MOÇO, M. K.; GAMA-RODRIGUES, E. F.; GAMA- RODRIGUES, A. C.; CORREIA, M. E. F. Caracterização da fauna edáfica em diferentes coberturas vegetais na região norte fluminense. Revista Brasileira de Ciência do Solo, Viçosa SP, v. 29, n. 4, p. 555-564, 2005.

ODUM, E. P. Ecologia. Rio de janeiro, Ed. Guanabara, 1986. 434p.

PIELOU, E. C. Mathematical ecology. New York: Wiley, 1977. 385 p.

PINHEIRO, A. Monitoramento e avaliação da qualidade das águas. In: RONEURI, A. R. (Org.). Avaliação e contabilização de impactos ambientais. Campinas, 2004. 204p.

PRIMAVESI, A. Manejo ecológico do solo: A agricultura em regiões tropicais. São Paulo: Nobel, 2002. 549p.

ROVEDDER, A. P. M.; ELTZ, F. L. F.; DRESCHER, M. S.; SCHENATO, R. B.; ANTONIOLLI , Z. I. Organismos edáficos como bioindicadores da recuperação de solos degradados por arenização no Bioma Pampa. Ciência Rural, Santa Maria, v. 39, n. 4, p. 1051-1058, 2009.

SHANNON, E. V. \& WEAVER, W. The Mathematical theory of Communication. Urbana. Illinois: University of Illinois Press, 1949. 17 p. 
SILVA, R. F. da; TOMAZI, M.; PEZARICO, C. R.; AQUINO, A. M. de; MERCANTE, F. M. Macrofauna invertebrada edáfica em cultivo de mandioca sob sistemas de cobertura do solo. Pesquisa Agropecuária Brasileira. Brasília, v. 42, n. 6, p. 865-871, 2007.

SILVA, R. F.; AQUINO, A. M. de.; MERCANTE, F. M.; GUIMARÃES, M. de F. Macrofauna invertebrada do solo sob diferentes sistemas de produção em Latossolo da Região do Cerrado. Pesquisa Agropecuária Brasileira, Brasília, v. 41, n. 4, p. 679-704, 2006.

STATSOFT, INC. STATISTICA (data analysis software system), versão 7 (2004). Disponível em: <www.statsoft.com>.

STEFFEN, R. B.; ANTONIOLLI, Z. I.; STEFFEN, G. P. K. Avaliação de substratos para reprodução de colêmbolos nativos em condições de laboratório. Ciência Florestal, Santa Maria, v. 17, n. 3, p. 265-269, 2007.

Submetido em: 20/04/2011

Aceito em: 04/12/2012 
